\title{
Exploring Different Mutations at a Single Amino Acid Position of Cucumber green mottle mosaic virus Replicase to Attain Stable Symptom Attenuation
}

\author{
Liming Liu, Bin Peng, Zhenwei Zhang, Yang Wu, Manuel Miras, Miguel A. Aranda, and Qinsheng Gu†
}

\begin{abstract}
First, second, third, fourth, and seventh authors: Henan Provincial Key Laboratory of Fruit and Cucurbit Biology, Zhengzhou Fruit Research Institute, Chinese Academy of Agricultural Sciences, Zhengzhou 450009, Henan, China; and fifth and sixth authors: Centro de Edafología y Biología Aplicada del Segura (CEBAS)-CSIC, Apdo. Correos 164, 30100 Espinardo, Murcia, Spain.
\end{abstract}

Accepted for publication 24 May 2017.

\begin{abstract}
Cucumber green mottle mosaic virus (CGMMV) is a member of the genus Tobamovirus (family Virgaviridae) that causes serious economic losses in cucurbit crops. A possibility for CGMMV control is the use of cross-protection, for which stable attenuated isolates are required. In this study, an infectious clone was constructed for the hn isolate of CGMMV. Unexpectedly, this clone carried a nonconserved mutation involving a single nucleotide change resulting in the replacement of Arg by Cys at residue 284 of the replicase protein; this mutation correlated with delayed symptom induction and RNA accumulation, as shown in time-course experiments. Sequencing of the viral progeny showed that restoration of wild-type symptoms and increased RNA accumulation correlated with reversion of the mutation to the wild-

type sequence, a phenomenon that occurred at approximately 7 to 10 days postinoculation. Thus, Arg284 seems to be crucial but not strictly necessary for virus infection. Subsequently, four other mutants in the triplet encoding Arg284 were constructed and assayed. Results showed that symptoms and their timing were diverse for the different mutants, with enhanced pathogenicity and RNA accumulation always correlating with reversion to Arg284. Therefore, the nature of the mutation strongly influenced the genetic stability of the mutant. At least two mutants were identified for which reversion did not occur by 30 days postinoculation, and these were defined as good candidates to attain stable symptom attenuation that could be useful in crossprotection.
\end{abstract}

Cucumber green mottle mosaic virus (CGMMV) causes serious economic losses in cucurbit crops. CGMMV is a member of the genus Tobamovirus in the family Virgaviridae and its genome consists of a 6,423-nucleotide, single-stranded positive-sense RNA molecule that encodes at least four proteins: the 129-KDa replication protein, which plays a role in the suppression of host RNA silencing; the 186-KDa viral replicase; the 29-KDa movement protein (MP); and the 17.4-KDa coat protein (Nishiguchi 2007; Ugaki et al. 1991). Like other tobamoviruses, CGMMV can be efficiently transmitted by mechanical means (e.g., farmer's hands and farm tools), is seed transmitted, and can persist in contaminated soils for long periods (Gooding and Hebert 1967; Li et al. 2016; Medvedskaya 1981; Reingold et al. 2015). CGMMV can cause mottling and mosaic symptoms on leaves and different degrees of mottling and deterioration of fruit of cucurbit plants (Park 2001; Reingold et al. 2015). CGMMV was first reported in the United Kingdom in 1935 (Ainsworth 1935); subsequently, it has spread among cucurbit crops worldwide (Ali et al. 2014; Al-Shahwan and Abdalla 1992; Li et al. 2015; Reingold et al. 2013; Rudnieva et al. 2005; Slavokhotova et al. 2007; Wang and Chen 1985; Yoon et al. 2008). CGMMV was identified as a quarantine pest in China in 2006 (Chen 2007). Cross-protection is an interesting means for the control of CGMMV-induced diseases. Indeed, it has been shown that the SH33b and VIROG-43M isolates of CGMMV induced attenuated symptoms in infected plants; therefore, they were good candidates for their use in cross-protection against CGMMV aggressive isolates (Nishiguchi 2007; Slavokhotova et al. 2016). Mild or attenuated isolates used in cross-protection need to be

†Corresponding author: E-mail: guqinsheng@ caas.cn

*The $\boldsymbol{e}$-Xtra logo stands for "electronic extra" and indicates that one supplementary table is published online.

(C) 2017 The American Phytopathological Society stable; however, this might not be the case for VIROG-43M, because severe mosaic symptoms were observed in a few plants inoculated with this CGMMV isolate (Slavokhotova et al. 2016). Due to the error-prone nature of RNA virus replication, adaptive variations can be rapidly gained in an ever-changing environment (Steinhauer et al. 1992). On numerous occasions, it has been reported that single mutations may act as major factors contributing to the adaptation of viruses (Fujita et al. 1996; Sasaki et al. 2001; Wallis et al. 2007). Thus, mutations associated with attenuation of the disease phenotype may be reversed through passages, as in the cases of symptom recovery of the attenuated isolate V-69 of Tobacco mosaic virus and the YM mutant of Pepino mosaic virus (Hasiów-Jaroszewska et al. 2013; Snegireva et al. 2005). Recombinant infectious clones represent valuable genetic tools for exploring the stability of mutations and their adaptive value (Hasiów-Jaroszewska et al. 2013; Snegireva et al. 2005); using infectious clones, point mutations can be introduced and their stability analyzed, providing information on the evolutionary role of specific genomic positions and also on diverse aspects of the host-virus interactions (Davenport and Baulcombe 1997; Rao and Hall 1993). Infectious clones for CGMMV have been previously reported (Ali et al. 2016; Kang et al. 2015; Ooi et al. 2006; Park et al. 2017; Zheng et al. 2015; Zhong et al. 2015).

In this study, we developed an agroinfectious cDNA clone for the hn isolate of CGMMV (GenBank accession KC851866). The clone contained a nonsynonymous mutation in a conserved position of the gene encoding the replicase protein. In spite of that, the clone was infectious and had genetically wild-type (WT) progeny. The mutation involved a single nucleotide substitution resulting in a missense amino acid replacement (Arg to Cys) at residue 284 of the replicase; after inoculation, position 284 reversed Cys to Arg. This initial result prompted us to test an array of mutations in the same position, to ascertain whether the nature of the mutation could affect its probability of reversion. Our results showed that this was, indeed, the case, paving the way for the design of new stably attenuated CGMMV isolates. 


\section{MATERIALS AND METHODS}

The construction of the CGMMV clones. The hn-CGMMV isolate was obtained from leaves of watermelon plants infected by CGMMV in Zhengzhou, Henan province, China. First, the virion was purified from virus-infected leaves following a protocol described for Tobacco mosaic virus (Gooding and Hebert 1967); next, viral genomic RNA was extracted from virions using RNAiso plus (TAKARA, Kyoto, Japan). M-MLV reverse transcription (RT) (TAKARA) was used for first-strand cDNA synthesis according to the manufacturer's protocol. The full-length cDNA was amplified as two fragments using Phusion High-Fidelity DNA Polymerase (New England Biolabs, Ipswich, MA). The 3'-terminal fragment was amplified using $3^{\prime}$ untranslated region (UTR) antisense primer and 2,083 sense primer and the polymerase chain reaction (PCR) fragment (approximately $4.6 \mathrm{~kb}$ ) was digested with $S m a \mathrm{I}$. Next, the product was inserted into vector pXT1, which was digested with SalI and SmaI, to generate pXT-CG-B. The 5'-terminal fragment was amplified using 5'UTR SP and 2,758 AP and the PCR fragment (approximately $2.7 \mathrm{~kb}$ ) was digested with StuI. Then, the product was inserted into pXT-CG-B, which was digested with StuI and SalI, to generate the full-length CGMMV clone, named pXTCGMMV. CGMMV mutants were constructed by site-directed mutagenesis according to the protocol of the Fast mutagenesis system (Transgen, Beijing, China).

Agrobacterium-mediated inoculation. The plasmids were transferred into Agrobacterium tumefaciens strain GV3101 by freeze-thaw transformation. A single colony from the transformation plate was transferred to Luria-Bertani broth containing rifampicin $\left(50 \mu \mathrm{g} \mathrm{ml}^{-1}\right)$ and kanamycin $\left(50 \mu \mathrm{g} \mathrm{ml}^{-1}\right)$ and were grown at $28^{\circ} \mathrm{C}$ overnight with vigorous shaking. The day after, the bacterial cells were harvested by centrifugation at $6,000 \times g$ for $5 \mathrm{~min}$, resuspended in induction buffer $\left(\mathrm{MgCl}_{2}\right.$ at $10 \mathrm{mmol}$ liter-1, morpholinoethanesulfonic acid at $10 \mathrm{mmol}$ liter $^{-1}$, and acetosyringone at $100 \mu \mathrm{mol}$ liter ${ }^{-1}$ ), adjusted to a final optical density at $600 \mathrm{~nm}$ of approximately 1.0 to 2.0 , and kept at room temperature for $2 \mathrm{~h}$ without shaking before agroinoculation. For agroinoculation, the cell suspension was injected by syringe into the abaxial intercellular space of cotyledons of watermelon, muskmelon, and bottle gourd. Agroinoculation of Nicotiana benthamiana plants (at the six- to eight-leaf stage) was performed by infiltration of the top two or three fully expanded leaves of 30-day-old plants. For each inoculum, more than three independent experiments were carried out, with at least nine plants inoculated for each experiment.

Double-antibody sandwich enzyme-linked immunosorbent assay. Double-antibody sandwich enzyme-linked immunosorbent assay (DAS-ELISA) was carried out according to the commercial ELISA kit instructions (Adgen, Auchincruive, UK). For each experiment, three plants were chosen and leaves were separately collected. The results were recorded by measuring the absorbance at $405 \mathrm{~nm}$ with a Model 550 Microplate reader (Bio-Rad, Hercules, CA). The raw ELISA readings were then averaged and converted to relative values using the following formula: (sample - blank)/(negative control - blank) (Chewachong et al.2015). The samples with an adjusted value of 3.0 or above were considered positive.

RNA analysis of CGMMV. Total RNA were extracted using TRIzol reagent (Invitrogen, Carlsbad, CA). For RT-PCR analysis, the first-strand cDNA was synthesized using 3'UTR AP according to the protocol of PeimescriptII RT (TAKARA) and RT-PCR was performed using the MP SP and 3'UTR AP, designed to amplify a 1,430-bp fragment according to the protocol of Taq polymerase (TAKARA). For Northern blot analysis of viral RNA, the instructions of the DIG Northern Starter Kit (Roche, Mannhein, Germany) were followed. Total RNA were separated on a $1.2 \%$ formaldehydeagarose gel and transferred to Hybond- $\mathrm{N}$ membranes (Amersham Biosciences, Little Chalfant, UK) with the vacu-Blot system (Biometra, Göttingen, Germany). Then, the membranes were hybridized with a digoxigenin (DIG)-labeled probe and were imaged by the Chemiluminescence lmaging System (Tanon, Shanghai, China). The probe was synthesized as follows: a PCR product was obtained using the plasmid of pXT1-CGMMV as template and primers 5903F/T7-3UTR, after which it was transcribed into RNA and labeled with DIG in an in vitro transcription reaction using DIG Northern Starter Kit (Roche). The probe was complementary to the 5,903- to 6,423-nucleotide sequence of the CGMMV genome.

Protein structure modeling. Three-dimensional (3D) structures for the CGMMV methyl-transferase domain were modeled using the I-TASSER server (Roy et al. 2010). Models were selected based on the top-ranked predictions, depending on their accuracy assessment derived from confidence and template modeling scores.

\section{RESULTS}

A full-length cDNA clone of hn-CGMMV triggers WT symptoms. A full-length cDNA clone of hn-CGMMV was constructed (pXT1-CGMMV) and used to transform A. tumefaciens strain GV3101. Agroinfiltration can be successfully done in cucurbits (Rhee et al. 2014; Zheng et al. 2015). Therefore, leaves of $N$. benthamiana, watermelon (Citrullus lanatus), muskmelon (Cucumis melo), and bottle gourd (Lagenaria siceraria) were agroinoculated using this clone and symptom development was recorded. At 15 days postinoculation (dpi), $N$. benthamiana and bottle gourd plants began to exhibit mosaic symptoms in systemic leaves (Fig. 1A), whereas watermelon and muskmelon plants showed symptoms at $20 \mathrm{dpi}$ (Fig. 1A). Accumulation of viral RNA in N. benthamiana and bottle gourd was analyzed by Northern blot. Three bands were observed in Northern blots of RNA extracted at 15 dpi from systemically infected leaves, which corresponded to genomic RNA, subgenomic RNA1, and subgenomic RNA2, respectively, whereas no bands were observed for extracts from the equivalent leaves of mock-inoculated plants (Fig. 1B). Symptoms were similar for the original hn-CGMMV isolate (WT) and the infectious clone pXT1-CGMMV, and the infection of CGMMV was confirmed in both cases by RT-PCR and DAS-ELISA (data not shown). $N$. benthamiana plants were mechanically inoculated using sap from hn-CGMMV-inoculated and pXT1-CGMMV-agroinoculated plants; visible systemic mosaic symptoms appeared in the plants inoculated with sap from both classes of plants at $7 \mathrm{dpi}$ (Fig. 1C).

Although the pXT1-CGMMV clone was infectious, sequencing of the complete cDNA insert revealed that it carried a missense mutation in its replicase open reading frame, with a replacement of nucleotide $\mathrm{C}$ by nucleotide $\mathrm{T}$ in position 910 of the CGMMV genome sequence, resulting in an amino acid replacement (Arg to Cys) at position 284 of the replicase. This residue is located in the Cterminal part of the methyltransferase domain of the CGMMV replicase (see below), and an alignment of 53 CGMMV genome sequences obtained from GenBank showed perfect conservation of the nucleotide triplet encoding residue 284 (CGT; data not shown), suggesting that C910 or Arg284 may be important for CGMMV infection.

Editing the pXT1-CGMMV triplet encoding amino acid residue 284 reverses the phenotype to the WT. Nucleotide $\mathrm{T}(910)$ was edited in the pXT1-CGMMV clone, giving rise to two new clones, named eWT and C284R. In eWT, the triplet TGT was replaced by CGT and, in C284R, it was replaced by AGA, with both new triplets encoding the residue present in the original CGMMV isolate (Arg). An analysis of the pathogenicity of eWT and C284R showed that both could infect $N$. benthamiana efficiently. Systemic mosaic symptoms began to appear in $N$. benthamiana plants at 7 dpi and evolved to conspicuous symptoms at 10 dpi (Fig. 2A), in contrast to the delayed timing of symptom appearance described above for the unedited clone. Accumulation of viral RNA was analyzed at 10 dpi by Northern blot, showing that both eWT and C284R produced abundant and similar amounts of RNA (Fig. 2B). For a better description of the infection timing, we compared the 


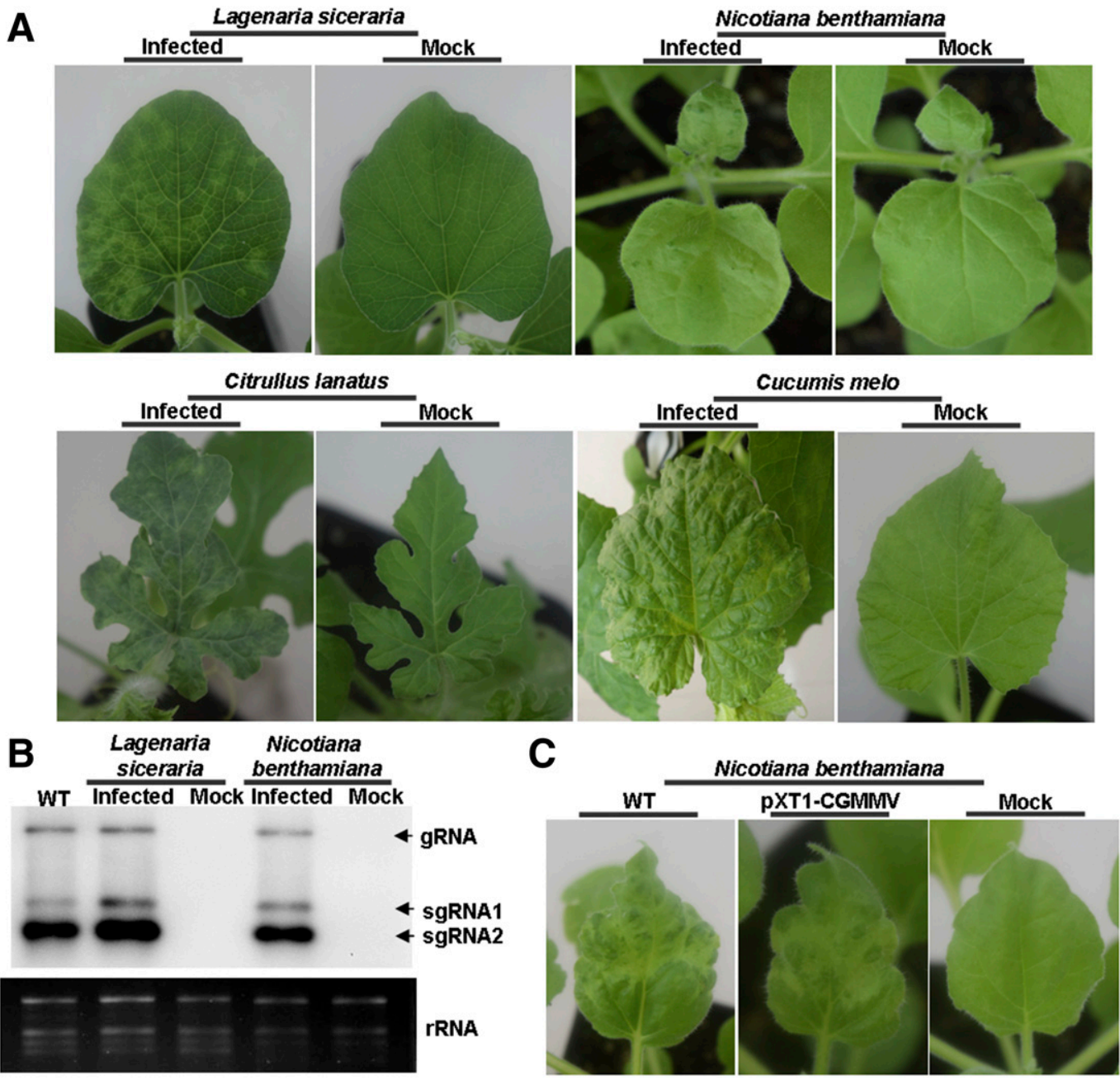

Fig. 1. pXT1-Cucumber green mottle mosaic virus (CGMMV) symptom induction and RNA accumulation. A, Symptoms induced by pXT1-CGMMV on bottle gourd (Lagenaria siceraria), Nicotiana benthamiana, watermelon (Citrullus lanatus), and muskmelon (Cucumis melo) at 15, 15, 20, and 20 days postinoculation (dpi), respectively. B, Northern blot analysis of total RNA extracted at 15 dpi from the systemic leaves of virus or mock-inoculated plants. Total RNA (1 $\mu \mathrm{g})$ for each sample was loaded and the SYBR-SAFE staining of the sample was displayed as loading control. Positions of viral genomic RNA and the two subgenomic RNA were displayed as gRNA, sgRNA1, and sgRNA2, respectively. WT = wild type and rRNA = ribosomal RNA. C, Symptoms induced at 7 dpi after mechanical inoculation of $N$. benthamiana leaves using sap from pXT1-CGMMV-infected plants.
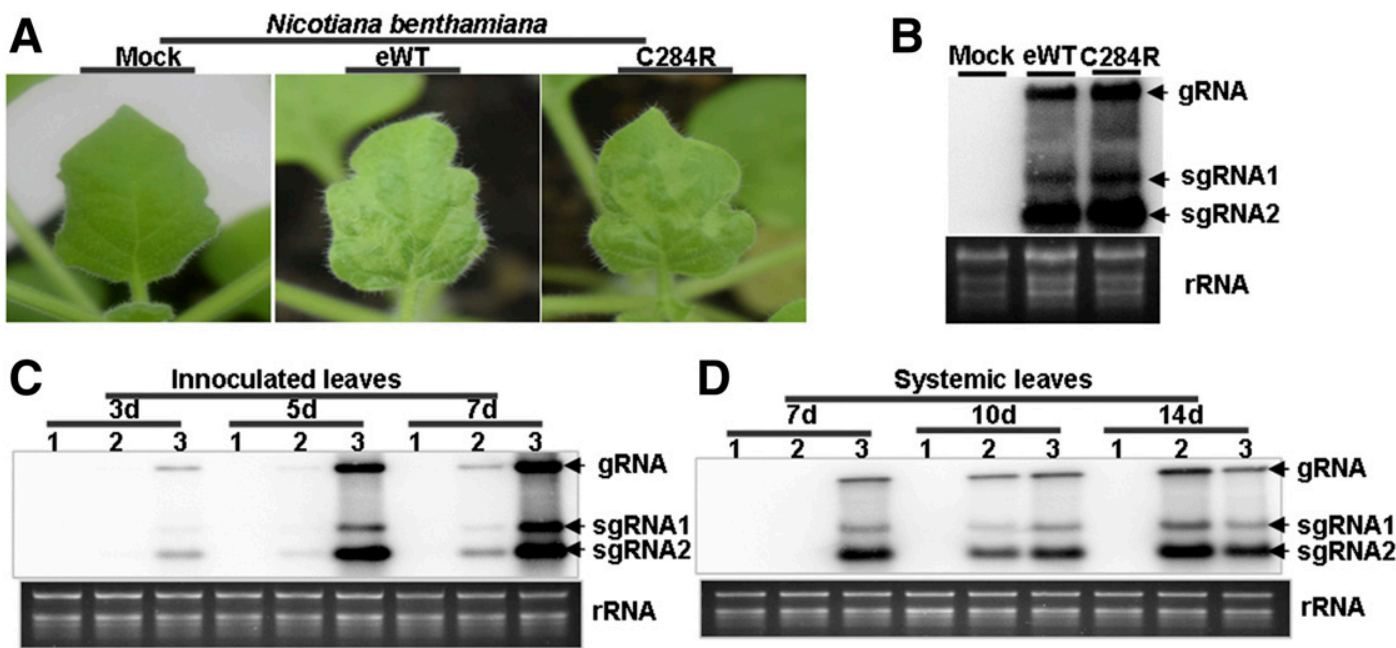

Fig. 2. eWT and C284R symptom induction and RNA accumulation and comparison of C284R and pXT1-Cucumber green mottle mosaic virus (CGMMV) RNA accumulation. A, Symptoms induced by eWT and C284R on Nicotiana benthamiana plants at 10 days postinoculation (dpi). B, Accumulation of viral RNA of eWT and C284R was analyzed by Northern blot in samples from systemically infected leaves of $N$. benthamiana at 10 dpi. Total RNA ( $2 \mu \mathrm{g})$ was loaded for each sample; gRNA = genomic RNA, sgRNA = subgenomic RNA, and rRNA = ribosomal RNA. C and D, Accumulation of viral RNA of C284R and pXT1-CGMMV was analyzed in inoculated leaves and systemic leaves of $N$. benthamiana. Total RNA $(2 \mu \mathrm{g})$ was loaded for each sample. Lane 1 , mock-inoculated plants; lane 2 , pXT1-CGMMV; and lane 3, C284R. 
accumulation of viral RNA from C284R and pXT1-CGMMV in a time course experiment by Northern blot. C284R RNA began to accumulate in inoculated leaves at $3 \mathrm{dpi}$ and, by $7 \mathrm{dpi}$, RNA were fully detectable in systemically infected leaves, whereas pXT1CGMMV RNA were detectable with a low intensity signal at 5 dpi in inoculated leaves and, in systemically infected leaves, only at $10 \mathrm{dpi}$

TABLE 1. Mutations assayed in Cucumber green mottle mosaic virus clones

\begin{tabular}{lccccc}
\hline Mutant & $\begin{array}{c}\text { Amino } \\
\text { acid }\end{array}$ & Codon & $\begin{array}{c}\text { Reverse } \\
\text { mutation }\end{array}$ & $\begin{array}{c}\text { Amino acid } \\
\text { polarity }\end{array}$ & $\begin{array}{c}\text { Side chain } \\
\text { charge }\end{array}$ \\
\hline R284K & Lys & AAG & None & Polar & Basic \\
R284H & His & CAT & CGT & Polar & Basic \\
R284A & Ala & GCT & None & Apolar & Neutral \\
R284S & Ser & TCT & None & Polar & Neutral \\
\hline
\end{tabular}

(Fig. 2C and D). Therefore, viral RNA of pXT1-CGMMV began to accumulate later and apparently to a lesser extent than those of C284R. In the same experiment, the nucleotide triplet encoding residue 284 was characterized by sequencing RT-PCR products. No changes were detected for $\mathrm{C} 284 \mathrm{R}$ along the entire time-course experiment. For pXT1-CGMMV, the original triplet from the clone (TGT) was sequenced at all time points in inoculated leaves but it changed to CGT at 10 and 14 dpi in systemic leaves. These data suggest that efficient CGMMV infection requires Arg at residue 284 , regardless of the triplet encoding it, and also that reversion T910C occurred at approximately 7 to $10 \mathrm{dpi}$.

Analysis of additional mutations at amino acid position 284. Our data indicated that amino acid replacement Arg to Cys at position 284 of the CGMMV replicase had an impact on the pathogenicity and accumulation of CGMMV, and that a nucleotide

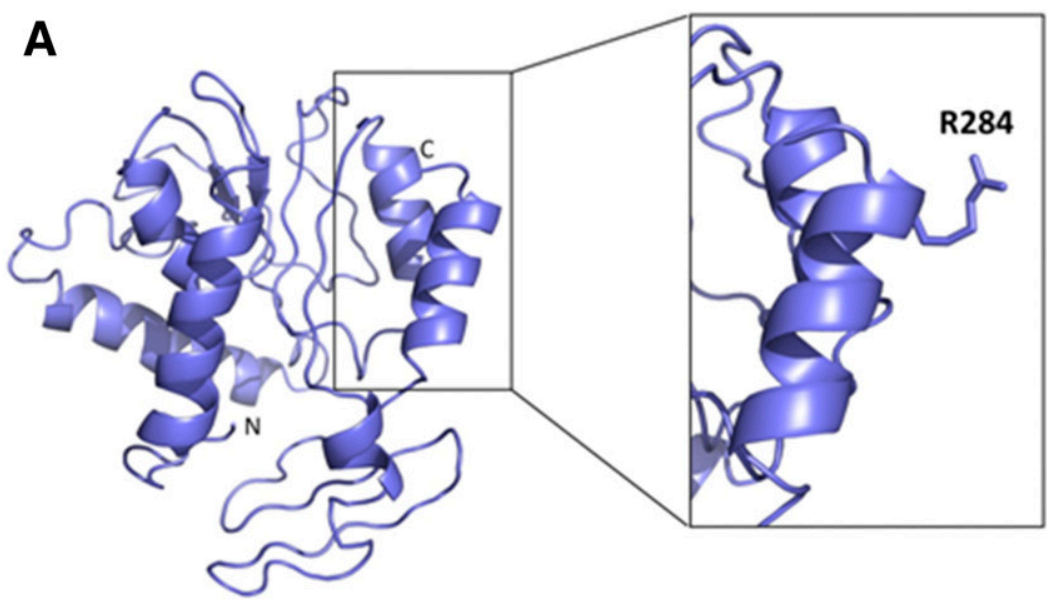

B
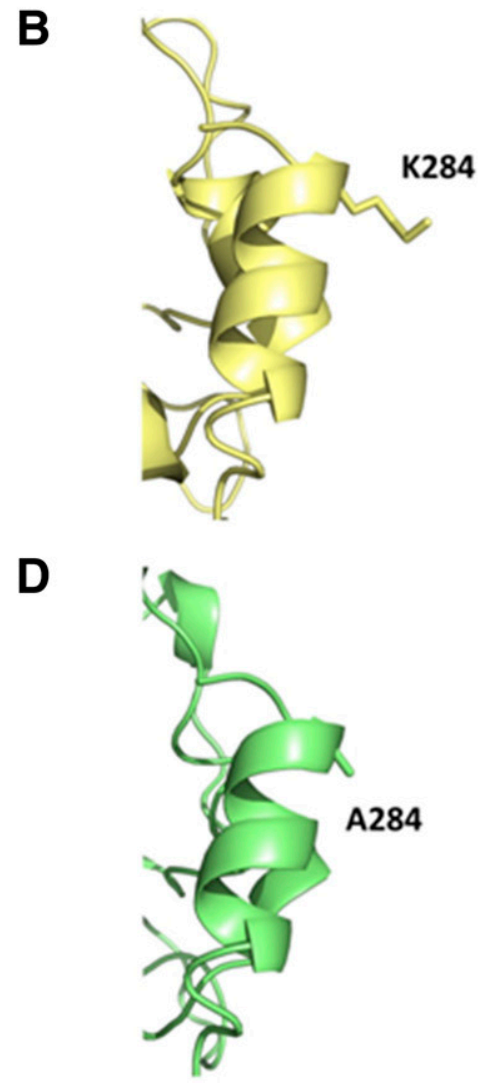

C

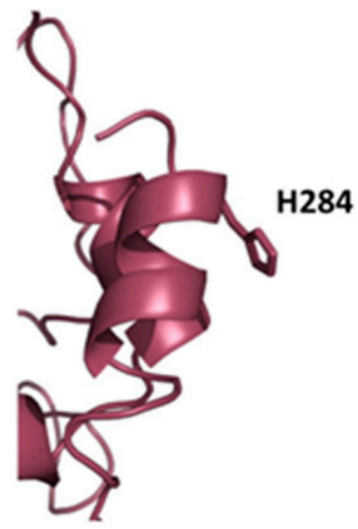

E

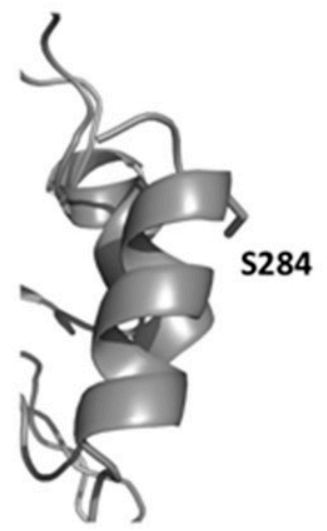

Fig. 3. Three-dimensional model of the methyltransferase domain of the Cucumber green mottle mosaic virus (CGMMV) replicase. A, Prediction of the methyltransferase domain from hn-CGMMV and close-up view of the C-terminal $\alpha$-helix, with residue Arg284 shown as a stick. B to E, Close-up views of the Cterminal helices of the hn-CGMMV methyltransferase domain with Lys, His, Ala, and Ser substitutions at position 284 shown as sticks. Models are based on the 72- to 287-amino-acid sequence of the CGMMV replicase, and inferred using the I-Tasser server (Roy et al. 2010). 
mutation giving rise to this replacement reverted soon after inoculation. We wondered whether spontaneous reversion could occur with a range of different nucleotide mutations and what would be the disease phenotype associated with different mutants. Therefore, four additional mutants were constructed (Table 1). In silico 3D modeling of the hn-CGMMV methyltransferase domain (amino acids 72 to 287 of the replicase) suggested the existence of two structured subdomains, consisting of two or three $\alpha$-helices each, separated by an apparently unorganized central region. Residue 284 is at the C-terminus of one of these subdomains, and seemed to protrude from the structure (Fig. 3A and inset). Therefore, replacement of Arg284 by other amino acids (Table 1) in the mutants may not significantly distort the methyltransferase subdomain structure (Fig. 3B to E).

Mutants were inoculated as previously described; symptoms and their timing were diverse for the different mutants. Mutant R284K induced symptoms at $10 \mathrm{dpi}$ and even severe mosaic symptoms at 15 dpi, which were indistinguishable from those induced by C284R (Fig. 4A). In contrast, symptoms induced by R284H, R284A, and R284S appeared later. R284H symptom severity increased with time and was identical to that of C284R by the end of the experiment, whereas mutants R284A and R284S induced mild symptoms that were maintained for more than $30 \mathrm{dpi}$ (Fig. 4C). DAS-ELISA confirmed CGMMV infection in all cases (data not shown). The accumulation of viral RNA was analyzed by Northern blot for all mutants at 15 and $30 \mathrm{dpi}$; results perfectly correlated with the severity of the disease induced by the mutants (Fig. 4B and D). RTPCR products around the mutated residues were sequenced in order to characterize the viral progenies. Reversion to Arg284 was found to occur for R284H but not for R284K, R284A, and R284S, suggesting again that Arg284 correlates with increased pathogenicity of the virus.

\section{DISCUSSION}

In this study, we constructed pXT1-CGMMV, an infectious clone of hn-CGMMV. Unexpectedly, sequencing of the full-length cDNA viral insert identified an undesigned mutation affecting a conserved nucleotide within the replicase open reading frame. This mutation gave rise to the amino acid replacement Arg284Cys. However, pXT1-CGMMV progeny in systemically infected plant tissues had the WT sequence, strongly suggesting that a reversion of the mutation occurred along the infection cycle of the virus. Editing pXT1CGMMV to reverse the mutation gave rise to clones eWT and C284R, which infected host plants efficiently and in a similar manner to the WT virus. Editing involved different nucleotide changes encoding reversion to the same amino acid, so that the pathogenicity phenotypes observed appeared to be mediated by the amino acid sequence rather than by the nucleotide sequence.

In order to investigate the role of residue Arg284 on the pathogenicity of CGMMV, another four mutants with different amino acids at position 284 were constructed. The characterization of the mutants showed that changes to His at residue 284 reversed to Arg (mutants R284H) but changes to Ala, Ser, and Lys at residue 284 (mutants R284A, R284S, and R284K, respectively) were retained, indicating that $\mathrm{Arg}$ at residue 284 was crucial but not strictly necessary for CGMMV infection. Moreover, the mutants R284A and R284S infected the host plants although with lower levels of viral RNA accumulation and mild symptoms, revealing that CGMMV tolerated the mutations with a trade-off in virulence. The replicase protein is considered to be a determinant of pathogenicity of CGMMV, and residue 284 seems to play an important role. This is supported by sequence analysis of other attenuated isolates of CGMMV, where mutations on the replicase open reading frame were also associated with the attenuated

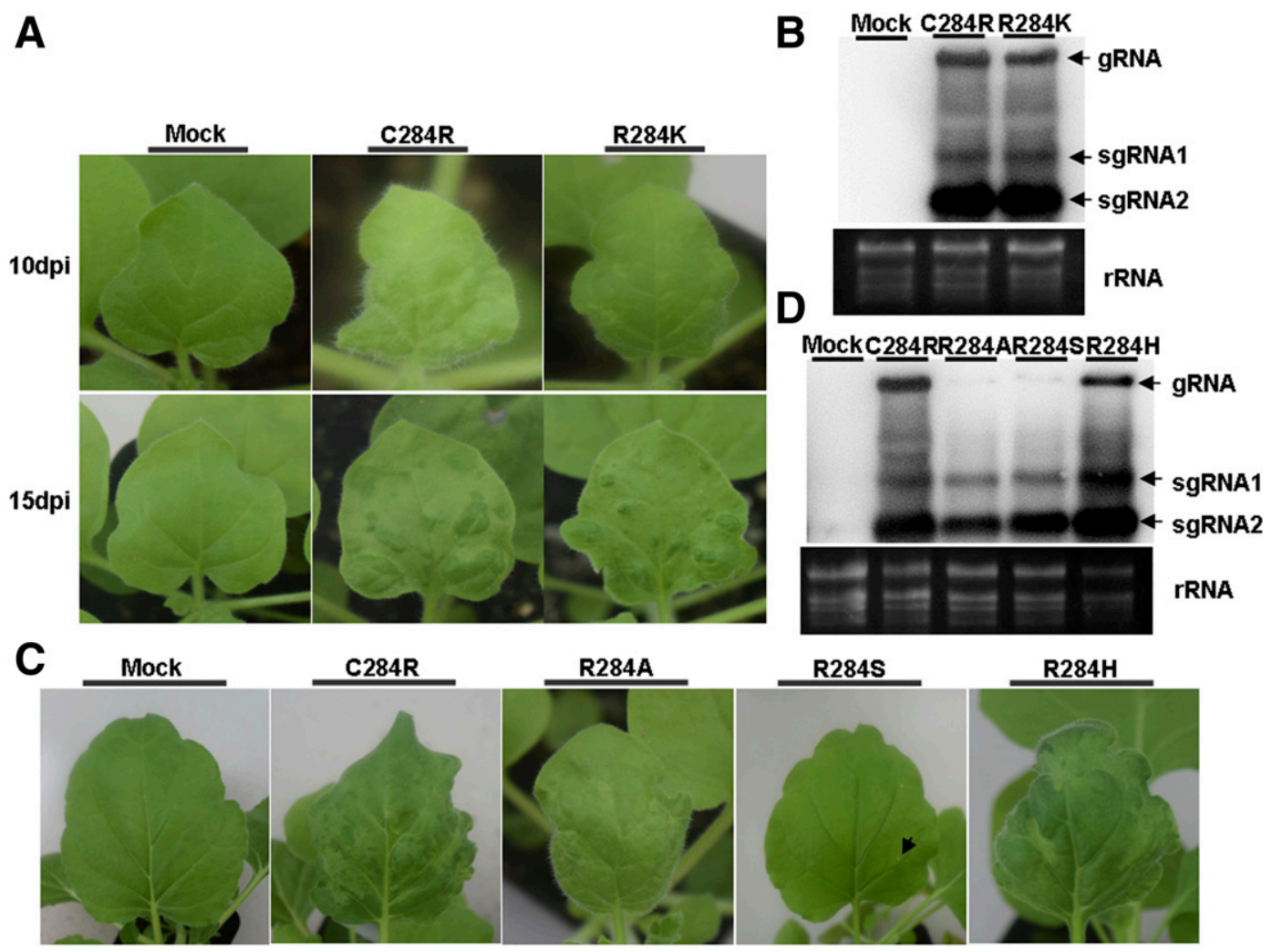

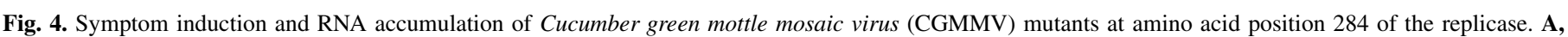

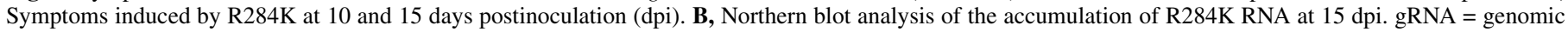

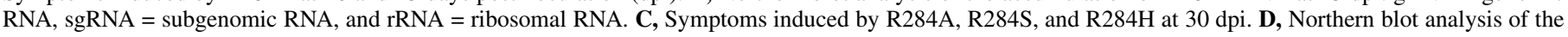

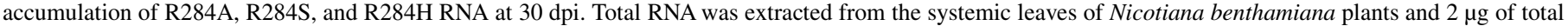
RNA was loaded for each sample for Northern blot analysis. 
pathogenicity of the virus (Slavokhotova et al. 2016). CGMMV replicase position 284 is located at the C-terminal part of the methyltransferase domain of the protein, and Arg284 is well conserved among tobamoviruses. Taking advantage of the I-Tasser server (http://zhanglab.ccmb.med.umich.edu/I-TASSER/) (Roy et al. 2010), we modeled the 3D structure of the hn-CGMMV methyltransferase domain, showing that residue 284 belonged to one of the structural subdomains that can be delineated in the peptide; Arg284 seemed to protrude from the structure, and its replacement appeared not to affect the subdomain organization. However, given the apparently exposed position of amino acid 284 and the hydrophobic core formed by adjacent residues (Leu280, Ile281, Val282, and Met283), substitutions at this position may have important effects on the interaction of the protein with its various partners, and this may have consequences on virus pathogenicity, because it seemed to be the case for the mutants tested in this work. An exception appeared to be R284K, for which viral RNA accumulation and disease severity were similar to the WT and mutation did not revert. Congruently, Lys and Arg had similar hydrophobicity profiles.

It has been reported that reverse mutations arise from error-prone replication and recombination in Brome mosaic virus (Rao and Hall 1993). Error-prone replication of CGMMV is the likely explanation in our case. Generally, reversions imply a single nucleotide change (Davenport and Baulcombe 1997; Hasiów-Jaroszewska et al. 2013; Snegireva et al. 2005), as in the case of some CGMMV mutants in this study. Logically, the more mutations in a virus genome, the less likely it is that reversion will occur (Maassab and Deborde 1985; Tosh et al. 2008). Also, reversions implying transition mutations are more likely to occur than those implying transversions. Taking all this into consideration, the likely stability of R284A should be superior to that of R284S, because reversion of the former mutant would imply two transversions whereas, for the later, one transition and one reversion would result in WT virus.

In summary, residue 284 of the replicase played a crucial role in the pathogenicity of CGMMV, providing a mutational target for symptom modulation, although it traded off virus survival. Viral fitness and the number of mutations, particularly transitions, required to reverse to the WT may play major roles in the stability of mutants. Our results pave the way for the design of potential mutations to gather a great number of attenuated viruses. Future work will reveal specific roles of the methyltransferase CGMMV protein domain in host-virus interactions.

\section{ACKNOWLEDGMENTS}

We thank X.-R. Tao (Nanjing Agricultural University, China) for providing plasmid $\mathrm{pXT} 1$. Work in the Spanish lab was funded by grant AGL2015-65838 (MINECO, Spain-FEDER). Work in the Chinese lab was jointly funded by the earmarked fund for the Modern Agroindustry Technology Research System (number CARS-26-13), the National Natural Science Foundation of China (31572147), and the Agricultural Science and Technology Innovation Program (CAAS-ASTIP-2015-ZFRI).

\section{LITERATURE CITED}

Ainsworth, G. C. 1935. Mosaic disease of the cucumber. Ann. Appl. Biol. 22: 55-67.

Ali, A., Hussain, A., and Ahmad, M. 2014. Occurrence and molecular characterization of Cucumber green mottle mosaic virus in cucurbit crops of KPK, Pakistan. Braz. J. Microbiol. 45:1247-1253.

Ali, M. E., Waliullah, S., and Nishiguchi, M. 2016. Molecular analysis of an attenuated strain of Cucumber green mottle mosaic virus using in vitro infectious cDNA clone: Pathogenicity and suppression of RNA silencing. J. Plant Biochem. Biotechnol. 25:79-86.

Al-Shahwan, I. M., and Abdalla, O. A. 1992. A strain of cucumber green mottle mosaic virus (CGMMV) from bottlegourd in Saudi Arabia. J. Phytopathol. 134:152-156.

Chen, J. L. M. 2007. An alien invasive pest-Cucumber green mottle mosaic virus. Plant Quar. 21:94-96.
Chewachong, G. M., Miller, S. A., Blakeslee, J. J., Francis, D. M. T., Jack, M., and Feng, Q. 2015. Generation of an attenuated, cross-protective Pepino mosaic virus variant through alignment-guided mutagenesis of the viral capsid protein. Phytopathology 105:126-134.

Davenport, G. F., and Baulcombe, D. C. 1997. Mutation of the GKS motif of the RNA-dependent RNA polymerase from potato virus $\mathrm{X}$ disables or eliminates virus replication. J. Gen. Virol. 78:1247-1251.

Fujita, Y., Mise, K., Okuno, T., Ahlquist, P., and Furusawa, I. 1996. A single codon change in a conserved motif of a bromovirus movement protein gene confers compatibility with a new host. Virology 223:283-291.

Gooding, G. V., Jr., and Hebert, T. T. 1967. A simple technique for purification of tobacco mosaic virus in large quantities. (Abstr.) Phytopathology 57:1285.

Hasiów-Jaroszewska, B., Paeleman, A., Ortega-Parra, N., Borodynko, N., Minicka, J., Czerwoniec, A., Thomma, B. P., and Hanssen, I. M. 2013. Ratio of mutated versus wild-type coat protein sequences in Pepino mosaic virus determines the nature and severity of yellowing symptoms on tomato plants. Mol. Plant Pathol. 14:923-933.

Kang, M., Seo, J. K., Song, D., Choi, H. S., and Kim, K. H. 2015. Establishment of an agrobacterium-mediated inoculation system for cucumber green mottle mosaic virus. Plant Pathol. J. 31:433-437.

Li, J.-X., Liu, S.-S., and Gu, Q.-S. 2016. Transmission efficiency of Cucumber green mottle mosaic virus via seeds, soil, pruning and irrigation water. J. Phytopathol. 164:300-309.

Li, R., Zheng, Y., Fei, Z., and Ling, K.-S. 2015. First complete genome sequence of an emerging cucumber green mottle mosaic virus isolate in North America. Genome Announce. 3:e00452-15.

Maassab, H. F., and Deborde, D. C. 1985. Development and characterization of cold-adapted viruses for use as live virus vaccines. Vaccine 3:355-369.

Medvedskaya, I. G. 1981. Virus diseases of glasshouse cucumber. Zashch. Rast. (Moscow) 5:44-45.

Nishiguchi, M. 2007. Basic studies on attenuated viruses. J. Gen. Plant Pathol. 73:418-420.

Ooi, A., Tan, S., Mohamed, R., Rahman, N. A., and Othman, R. Y. 2006. The full-length clone of cucumber green mottle mosaic virus and its application as an expression system for hepatitis B surface antigen. J. Biotechnol. 121: 471-481.

Park, C.-H., Ju, H.-K., Han, J.-Y., Park, J.-S., Kim, I.-H., Seo, E.-Y., Kim, J.-K., Hammond, J., and Lim, H.-S. 2017. Complete nucleotide sequences and construction of full-length infectious cDNA clones of cucumber green mottle mosaic virus (CGMMV) in a versatile newly developed binary vector including both $35 \mathrm{~S}$ and T7 promoters. Virus Genes 53:286-299.

Park, G. S. 2001. Occurrence of two tobamovirus diseases in cucurbits and control measures in Korea. Plant Pathol. J. 17:243-248.

Rao, A. L., and Hall, T. C. 1993. Recombination and polymerase error facilitate restoration of infectivity in brome mosaic virus. J. Virol. 67:969-979.

Reingold, V., Lachman, O., Blaosov, E., and Dombrovsky, A. 2015. Seed disinfection treatments do not sufficiently eliminate the infectivity of $\mathrm{Cu}$ cumber green mottle mosaic virus (CGMMV) on cucurbit seeds. Plant Pathol. 64:245-255.

Reingold, V., Lachman, O., Koren, A., and Dombrovsky, A. 2013. First report of Cucumber green mottle mosaic virus (CGMMV) symptoms in watermelon used for the discrimination of non-marketable fruits in Israeli commercial fields. New Dis. Rep. 28:11.

Rhee, S. J., Hong, J. S., and Lee, G. P. 2014. Infectivity and complete nucleotide sequence of cucumber fruit mottle mosaic virus isolate $\mathrm{Cm}$ cDNA. Arch. Virol. 159:1807-1811.

Roy, A., Kucukural, A., and Zhang, Y. 2010. I-TASSER: A unified platform for automated protein structure and function prediction. Nat. Protoc. 5: 725-738.

Rudnieva, T. O., Budzanivs'Ka, I. H., Aie, R., Shevchenko, T. P., Dem'Ianenko, F. P., and Polishchuk, V. P. 2005. Characteristics of green mottle mosaic virus isolates in cucumbers from different regions of Ukraine. Mikrobiol. Zh. 67:96-103.

Sasaki, N., Fujita, Y., Mise, K., and Furusawa, I. 2001. Site-specific single amino acid changes to Lys or Arg in the central region of the movement protein of a hybrid bromovirus are required for adaptation to a nonhost. Virology 279:47-57.

Slavokhotova, A. A., Andreeva, E. N., Shiian, A. N., Odintsova, T. I., and Pukhal'Skil, V. A. 2007. Specifics of the coat protein gene in Russian strains of the cucumber green mottle mosaic virus. Russ. J. Genet. 43: 1221-1226.

Slavokhotova, A. A., Istomina, E. A., Andreeva, E. N., Korostyleva, T. V., Pukhalskij, V. A., Shijan, A. N., and Odintsova, T. I. 2016. An attenuated strain of cucumber green mottle mosaic virus as a biological control agent against pathogenic viral strains. Am. J. Plant Sci. 07:724-732.

Snegireva, P. B., Istomina, E. A., and Shiian, A. N. 2005. A single reverse mutation in the 126/183-kda replicase gene of the attenuated tomato strain V-69 of tobacco mosaic virus increases the virus pathogenicity. Russ. J. Genet. 41:32-39. 
Steinhauer, D. A., Domingo, E., and Holland, J. J. 1992. Lack of evidence for proofreading mechanisms associated with an RNA virus polymerase. Gene 122:281-288.

Tosh, P. K., Boyce, T. G., and Poland, G. A. 2008. Flu myths: Dispelling the myths associated with live attenuated influenza vaccine. Mayo Clin. Proc. 83:77-84.

Ugaki, M., Tomiyama, M., Kakutani, T., Hidaka, S., Kiguchi, T., Nagata, R., Sato, T., Motoyoshi, F., and Nishiguchi, M. 1991. The complete nucleotide sequence of cucumber green mottle mosaic virus (SH strain) genomic RNA. J. Gen. Virol. 72:1487-1495.

Wallis, C. M., Stone, A. L., Sherman, D. J., Damsteegt, V. D., Gildow, F. E., and Schneider, W. L. 2007. Adaptation of plum pox virus to a herbaceous host (Pisum sativum) following serial passages. J. Gen. Virol. 88: 2839-2845.
Wang, S. M., and Chen, M. J. 1985. A new strain of cucumber mottle mosaic virus causing mosaic symptoms on bottlegourd in Taiwan. Plant Prot. Bull. (Taipei, Taiwan) 27:105-110.

Yoon, J. Y., Choi, G. S., Choi, S. K., Hong, J. S., Choi, J. K., Kim, W., Lee, G. P., and Ryu, K. H. 2008. Molecular and biological diversities of $\mathrm{Cu}$ cumber green mottle mosaic virus from cucurbitaceous crops in Korea. J. Phytopathol. 156:408-412.

Zheng, H., Xiao, C., Han, K., Peng, J., Lin, L., Lu, Y., Xie, L., Wu, X., Xu, P., and Li, G. 2015. Development of an agroinoculation system for full-length and GFP-tagged cDNA clones of cucumber green mottle mosaic virus. Arch. Virol. 160:2867-2872.

Zhong, M., Zhao, X., Liu, Y., Wang, Y., and Cao, K. 2015. Completion sequence and cloning of the infectious cDNA of a chb isolate of cucumber green mottle mosaic virus. Acta Virol. 59:49-56. 